\title{
Experimental Study on the Application of BOTDA in the Overlying Strata Deformation Monitoring Induced by Coal Mining
}

\author{
Jing Chai $\mathbb{D}^{1,2}$ and Wengang Du $\mathbb{D}^{1}$ \\ ${ }^{1}$ College of Energy Engineering, Xi'an University of Science and Technology, Xi'an 710054, China \\ ${ }^{2} X i$ 'an University of Science and Technology, Ministry of Education of the Western Mining and Mine Disaster Prevention and Control \\ of Key Laboratory, Xi'an 710054, China
}

Correspondence should be addressed to Wengang Du; 403870017@qq.com

Received 7 November 2018; Revised 23 January 2019; Accepted 29 January 2019; Published 16 April 2019

Academic Editor: Qiang Wu

Copyright (c) 2019 Jing Chai and Wengang Du. This is an open access article distributed under the Creative Commons Attribution License, which permits unrestricted use, distribution, and reproduction in any medium, provided the original work is properly cited.

\begin{abstract}
The coal mine working face overlying strata is often disturbed by multiple mining, leading to adverse effects on the working face's safe production and ground surface movement. In the three-dimensional physical model test with the size of $3000 \times 2000 \times 2000$ $\mathrm{mm}$, after the overburden gets stable when the first working face had been extracted, by using three vertical distributed optical fibers based on the BOTDA principle, the deformation law of the overburden caused by the contiguous coal face mining is studied. Results show that, before the working face advanced to $840 \mathrm{~mm}$ (near the fiber), the stress law of the overburden was as follows: the middle of the model was under pressure state and the remaining part was under tension state, and the key stratum produced stress concentration phenomena caused by the secondary mining; when the face advanced to $840 \mathrm{~mm}$ (through the fiber), the frequency shift curve of the key stratum and the strata on it combined, and the stress concentration in the key stratum disappeared, indicating that the bearing structure of the key stratum gets unstable; compared with the previous monitoring data, when the working face far away from the fiber, the information reflected by the frequency shift data gradually gets single when the working face is far away from the fiber compared with the previous measurement data. The overburden deformation increased dramatically after the key stratum gets unstable. The surrounding rock and fiber will detach when the stratum goes though large deformation such as abscission layer, fracture, and collapse, and the frequency shift monitored by BOTDA cannot characterize the rock deformation in this situation. The experimental method and the results of this paper serve as useful reference for the application of BOTDA technology in geotechnical engineering.
\end{abstract}

\section{Introduction}

The coal mine working face overlying strata is often disturbed by multiple mining, such as compound mining, slice mining, and adjacent face mining; the movement law of overburden gets complex due to multiple mining disturbance. The overburden is finally in a steady state after undergoing the processes of fracture and collapse. The multiple mining disturbance may intensify the damage degree of the roof and lead to adverse effects on coal mine safe production and ground surface movement.

Many scholars have done a lot of researches about multiple mining disturbances. Lu [1] evaluated the mining ability of the old coal mine, which can provide reference for the reuse of residual coal by fully mechanized mining technology; Feng et al. [2] took the residual mining area as the background and put forward the feasibility theory and judgment formula; Gong took the Shaanxi Coal Group Sheng-Hua Coal 3101 mining face as the project background, and the similarity simulation was used to study the characteristics of the roof crack and the pressure distribution in the face; $\mathrm{He}$ et al. [3] studied the roof caving of a roadway in Xing-An coal mine and gained the instability mechanism and prevention measures; and Fang et al. [4] studied on the E12505 working face frequent roof caving phenomenon in Cuijiazhai mine and gained the instability mechanism and protective measures. At present, researches on multiple disturbance are mainly focused on roadway support technology, 
the feasibility of compound mining, and so on; nevertheless, the research on the again deformation of the overburden after multiple disturbance of coal mining is a rare sight. The deformation and movement of overburden caused by mining activity are a typical "gray structure" problem; the physical similar material model test is one of the main research methods to study the law of strata movement and mine pressure [5]. In the traditional physical model test, single-point pattern sensors such as dial indicator, total station, strain gauge, and pressure gauge are often used to monitor the deformation; they can only gain the external deformation information of the surrounding rock, but to achieve multiscale distributed monitoring within the model is difficult, and there are a large number of sensors and data transmission lines. They will affect the material property and reduce the scientific nature of the experiment. The internal deformation monitoring is still a technical difficulty in a physical similar model experiment.

In recent years, fiber optic sensing technology has made a major breakthrough; it can provide a new way for structural deformation monitoring. Compared with traditional resistive or vibrating-wire strain sensors, optic fiber sensors have the advantages of antielectromagnetic, anticorrosion, and high sensitivity, and layout patterns can be distributed. If the sensor is installed in the tunnel, pile foundation, dam, and other linear structures, like the human nervous system as the perception of structural deformation, it can achieve remote real-time monitoring of the structure [6]. BOTDA has been widely applied to civil and industry infrastructure monitoring [7-9]. In 1990, Mendez et al. firstly applied fiber optic sensing technology to concrete structure health monitoring [10]. In order to improve BOTDA performance such as sensing distance and spatial resolution, many research works have been done. Especially, optical pulse coding and distributed first-order and second-order Raman amplification technology have made it possible to extend the sensing range beyond $100 \mathrm{~km}$ with a short spatial resolution [11, 12]. At the end of the last century, domestic scholar Liu firstly introduced the optic fiber sensing technology to the field of domestic geotechnical engineering [13]; Chai et al. [14, 15] used FBG technology to monitor the shaft deformation caused by quaternary unconsolidated layer settlement and verified the reliability of the FBG technique. Optical fiber sensing technology used in the field of geotechnical engineering research and engineering site has broad prospects.

\section{Working Principle of BOTDA}

The Brillouin optical time-domain analysis technique (BOTDA) was proposed by T. Horiguchi and M. Tateda in 1989 [16]. Compared with the BOTDA system, PPPBOTDA (pulse pre-pump Brillouin optical time domain analysis) employs the pump pulse with leakage light to achieve a higher spatial resolution. In order to gain a higher spatial resolution, the usual way is to reduce the pulse beam width. However, as the excitation of phonon takes $28 \mathrm{~ns}$, shortening the pulse width will lead to the decrease in Brillouin gain and the deterioration of spectral morphology. The PPP-BOTDA technique excites phonons by changing the shape of the pump light and adding a pre-pumped pulse wave before the measured pulse light is emitted. With this method, a $1 \mathrm{~cm}$ sampling interval and $5 \mathrm{~cm}$ spatial resolution can be obtained simultaneously [17].

Based on the Brillouin scattering principle, the continuous detection optical signal and pump pulse optical signal were injected from the two ends of the fiber, when the frequency difference between the continuous light and pulse light is equal to the Brillouin frequency shift in a region of the fiber; the region will produce a stimulated Brillouin amplification effect. The frequency of the two lasers is continuously adjusted. The relationship between temperature, strain, and Brillouin frequency shift is shown in the following equation:

$$
\begin{aligned}
\delta_{v \mathrm{~B}} & =C_{v \varepsilon} \delta \varepsilon+C_{v \mathrm{~T}} \delta T, \\
\frac{\delta_{\mathrm{PB}}}{P_{\mathrm{B}}} & =C_{\mathrm{P} \varepsilon} \delta \varepsilon+C_{\mathrm{PT}} \delta T,
\end{aligned}
$$

where $\delta_{v \mathrm{~B}}$ is the change of Brillouin frequency shift, $\delta_{\mathrm{PB}}$ is the relative change of Brillouin power, $\delta_{\varepsilon}$ and $\delta_{\mathrm{T}}$ are the strain and temperature change, $C_{\nu \varepsilon}$ and $C_{\nu \mathrm{T}}$ are the strain coefficient and temperature coefficient, and $C_{\mathrm{P \varepsilon}}$ and $C_{\mathrm{PT}}$ are the Brillouin power strain coefficient and Brillouin power temperature coefficient. The BOTDA system architecture is shown in Figure 1 [18]. The strain and temperature information of the optical fiber is obtained by detecting the frequency shift variation of the Brillouin signal and the normalized signal power variation value to achieve distributed testing.

\section{Model Test Design}

3.1. Text General Situation. The model test is based on the geological survey of the overlying strata in a working face of the Qianqiu Coal Mine. The total thickness of the coal seam and its overburden is $805.32 \mathrm{~m}$. A conglomerate is developed at $209.5 \mathrm{~m}$ above the coal seam, and the total thickness of the conglomerate is $410.2 \mathrm{~m}$, its tensile strength is $5.5 \mathrm{MPa}$, and the average compressive strength is $75 \mathrm{MPa}$, which belongs to the typical hard rock. The geometric similarity ratio is $1: 400$, the model size is $3000 \times 2000 \times 2000 \mathrm{~mm}$, the thickness of the simulated floor is $200 \mathrm{~mm}$, the thickness of the overburden is $1740 \mathrm{~mm}$, and the thickness of coal seam is $60 \mathrm{~mm}$. The physical and mechanical parameters of the main coal strata are shown in Table 1.

The physical model is not simulated to the ground surface, the remaining rock mass load is loaded with sandbags, and the material dosage is: $19.9 \mathrm{t}$ sand, $1.0 \mathrm{t}$ gypsum, and $1.7 \mathrm{t}$ lime. The real picture of the physical model is shown in Figure 2.

The boundary coal pillar with the width of $600 \mathrm{~mm}$ is left on both sides of the model. The working face is $2400 \mathrm{~mm}$ in length and $800 \mathrm{~mm}$ in width, and two working faces are excavated. The excavation step is $40 \mathrm{~mm}$. The excavation of the working face is simulated by extraction of galvanized steel pipe. The mining method is shown in Figure 3.

3.2. Monitoring System. Three vertical fibers were embedded in the overlying strata of face 1 in the laying process. The 


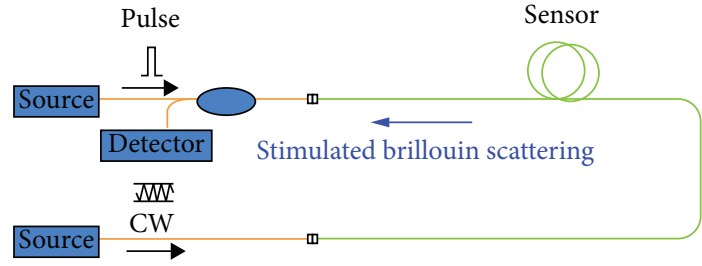

FIgURE 1: The system architecture of BOTDA.

TABLE 1: Physical and mechanical parameters of coal and rock.

\begin{tabular}{lcccc}
\hline Lithology & $\begin{array}{c}\text { Bulk } \\
\left(\mathrm{t} / \mathrm{m}^{3}\right)\end{array}$ & $\begin{array}{c}\text { Com } \\
(\mathrm{MPa})\end{array}$ & $\begin{array}{c}\text { Tens } \\
(\mathrm{MPa})\end{array}$ & $\begin{array}{c}\text { Elas }\left(10^{3}\right. \\
\mathrm{MPa})\end{array}$ \\
\hline Coal & 0.95 & 16 & 0.6 & 3.5 \\
Mudstone & 1.97 & 50 & 1.2 & 5 \\
Siltstone & 1.7 & 45 & 4 & 28 \\
Conglomerate & 1.83 & 75 & 5.5 & 32 \\
$\begin{array}{l}\text { Fine } \\
\text { sandstone }\end{array}$ & 1.67 & 30 & 4 & 35 \\
\hline
\end{tabular}

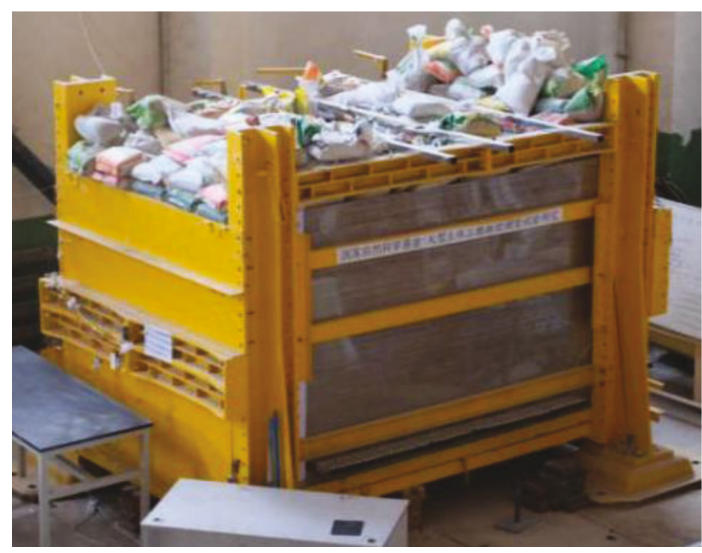

FIGURE 2: Three-dimensional model.

identifiers of the vertical fibers are $V_{11}, V_{12}$, and $V_{13}$, respectively, and the optical fiber sensor layout pattern is shown in Figure 4 . The red number is $V_{11}$, green for $V_{12}$, and black for $V_{13}$; they are located above working face 1 . The instrument type is NBX-6055, the spatial resolution is $5 \mathrm{~cm}$, and the sampling interval is $1 \mathrm{~cm}$.

The frequency shift value of the distributed fiber is the response of the sensor fiber to the external change. When the sensor fiber is embedded in the overburden, the different degrees of overburden deformation and collapse will cause different frequency shift variation.

\section{Results and Analysis}

4.1. Optical Fiber Test Data. Figure 5 shows the optical fiber $V_{11}$ 's frequency shift data when working face 2 was mining. The abscissa is the Brillouin frequency shift, and the ordinate is the model height. Figures 5(a) 5(f) are, respectively, working face 2 advancing to $0,480,680,840,1440$, and $2400 \mathrm{~mm}$.
The initial state of the optical fiber $V_{11}$ changes in frequency shift to $0 \mathrm{MHz}$ (Figure 5(a)). The frequency shift curve presents a 3-segment distribution when face 2 advanced to $480 \mathrm{~mm}$, the frequency shift of part 1 and part 3 are positive, and part 2 is negative (Figure 5(b)). Compared with advancing to $360 \mathrm{~mm}$, the curve adds 3 peaks in the lower part of the model when advancing to $480 \mathrm{~mm}$, and there is a peak in the conglomerate location. The height of the caving zone is about $0 \sim 500 \mathrm{~mm}$ after face 1 mining, the peak of part 1 is in the face 1 caving zone range, and face 2 mining caused the broken rock in the caving zone to move again. The frequency shift curve when advancing to $680 \mathrm{~mm}$ is shown in Figure 5(c); same as before, the fiber is still under compression in the middle part and under tension at both ends, and the frequency shift fluctuation gets severe compared with advancing to $480 \mathrm{~mm}$, indicating that the degree of influence caused by Re mining has increased as the face continues to advance. The frequency shift curve when advancing to $840 \mathrm{~mm}$ is shown in Figure 5(d); the curve has a large change compared with previous ones. The curve became a 2-part distribution from being a 3-part distribution; the frequency shift is negative in the range of $700 \sim 1740 \mathrm{~mm}$ and is positive in the range of $0 \sim 700 \mathrm{~mm}$, the curve gets smooth gradually, and no peak phenomenon appears. The frequency shift curve when advancing to $1440 \mathrm{~mm}$ is shown in Figure 5(e). Most of the frequency shift value is negative; it is positive only in the lower part of the model range from 400 to $800 \mathrm{~mm}$. The frequency shift curve when advancing to $2400 \mathrm{~mm}$ is shown in Figure 5(f), and the whole face 2 excavation is over at this time. After face 2 is far away from the optic fiber, the frequency shift is mainly negative, and the absolute value increases gradually with face 2 advancing forward.

It can be seen that the contact relationship changed between the fiber and the surrounding rock from $V_{11}$ 's frequency shift. The stress state of the fiber gets complex from being simple gradually, which indicates that the fiber is gradually detaching with the surrounding rock; it cannot characterize the stress state of the surrounding rock in this situation. The surrounding rock of face 1 is in a stable state before face 2 mining; then, the balance of the surrounding rock stress state was broken after face 2 mining, and the stress of the surrounding rock is redistributed. Before face 2 advanced to $840 \mathrm{~mm}$, the stress law of overburden is as follows: the middle part is under pressure and both the ends are under tension, the secondary mining caused the key stratum stress concentrating, and the mutation of the frequency shift indicates that the nearby strata are in a violent activity. When face 2 advanced to $840 \mathrm{~mm}$, the frequency shift curve of the key stratum and the strata on it combined and the stress concentration in the key stratum disappeared, indicating that the bearing structure of the key stratum gets unstable.

\subsection{Contrastive Analysis of Two Working Face Data}

4.2.1. Working Face near the Fiber. Figure 6 shows the frequency shift curve of the two working faces in the process near the fiber. Comparing the absolute value, the frequency shift peak is $300 \mathrm{MHz}$ when face 1 mined to $560 \mathrm{~mm}$ and is 

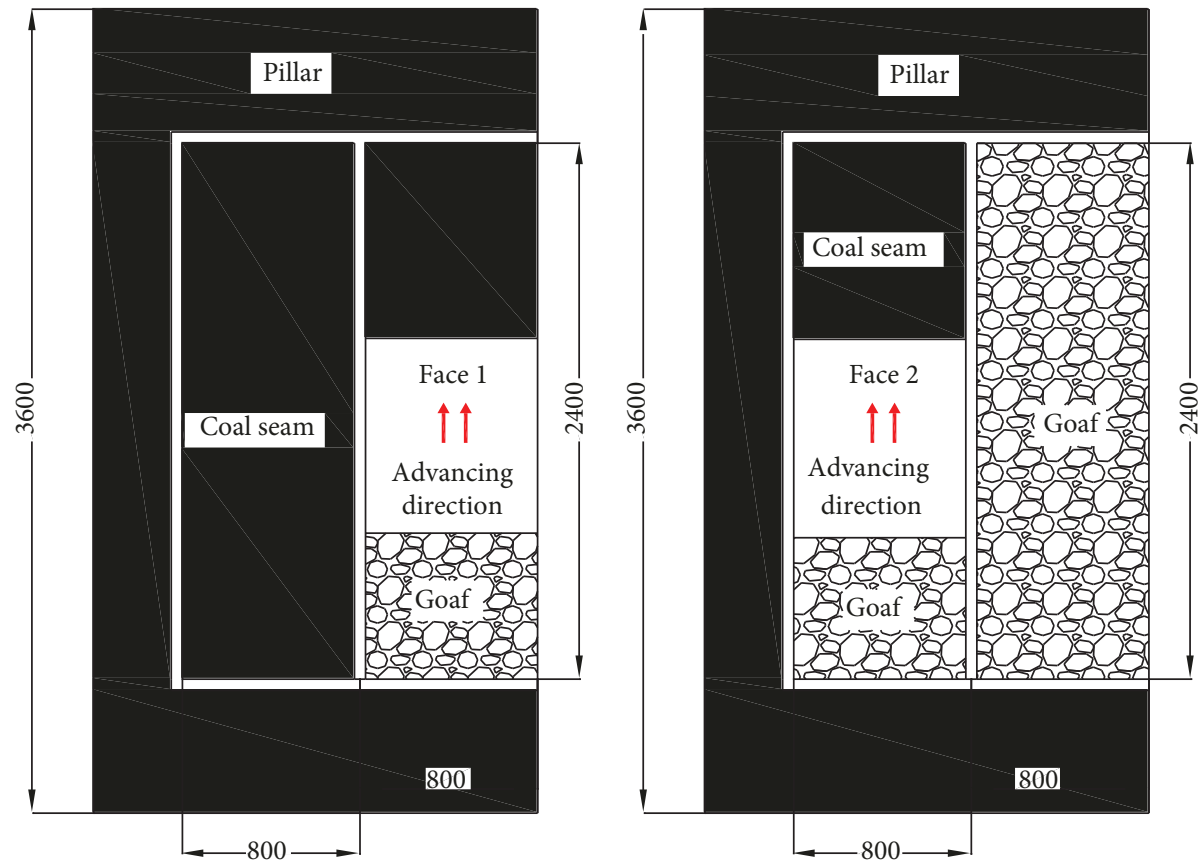

FIgURE 3: Mining style of the working face.

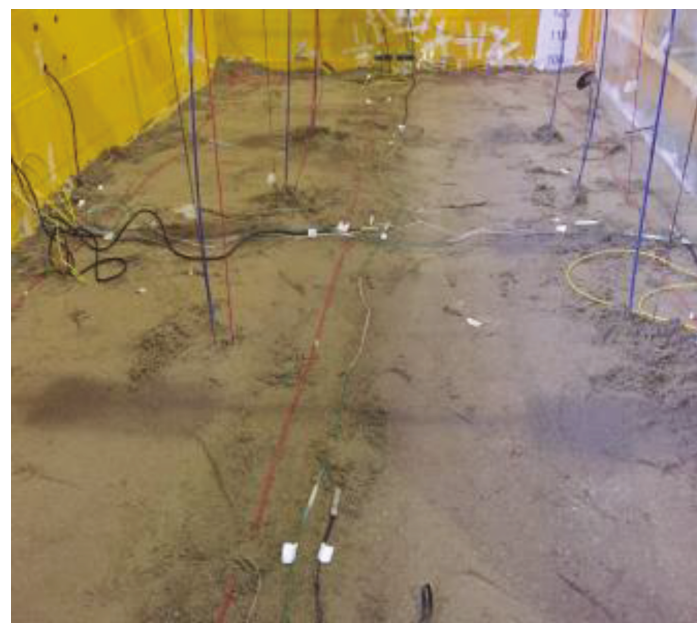

(a) Vertical fiber layout real picture

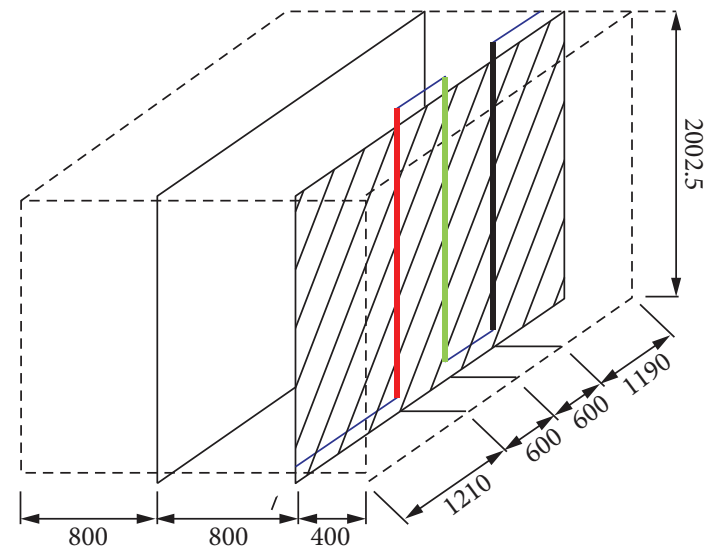

(b) Vertical fiber spatial location

FIgURE 4: Optical fiber sensor layout pattern.

$90 \mathrm{MHz}$ when face 2 mined to $560 \mathrm{~mm}$; it is much lower than face 1 mining. Because face 2 is far away from the optic fiber, the elastic deformation energy impact induced by mining has a large consumption when transferring to fiber $V_{11}$. Moreover, the overlying stratum above the working face 1 has been destroyed, rock storage potential elastic energy has been fully released, and face 2 mining will affect the overlying strata movement of face 1 , but the impact is much smaller than the mining face below it. When the working face 1 is close to $V_{11}$, the fiber is in the pressure state in the range of $0 \sim 500 \mathrm{~mm}$. The closer the working face is to the fiber, the larger the frequency shift is; the change of the frequency shift is caused by the advance abutment pressure in front of working face 1 ; when working face 2 is close to $V_{11}$, the frequency shift is the 3-part distribution, the middle part is under pressure, and the remaining was under tension; the secondary mining caused the key stratum stress to be concentrated.

4.2.2. Working Face through the Fiber. Figure 7 shows the frequency shift curve of the two working faces in the process through the fiber. As shown in Figure 7(a), when face 2 is through the optical fiber, the frequency shift curve is the 2part distribution, the frequency shift of part 1 is positive, the fiber is in tension state, and the frequency shift of part 2 is negative indicating that the fiber is in a compression state. 


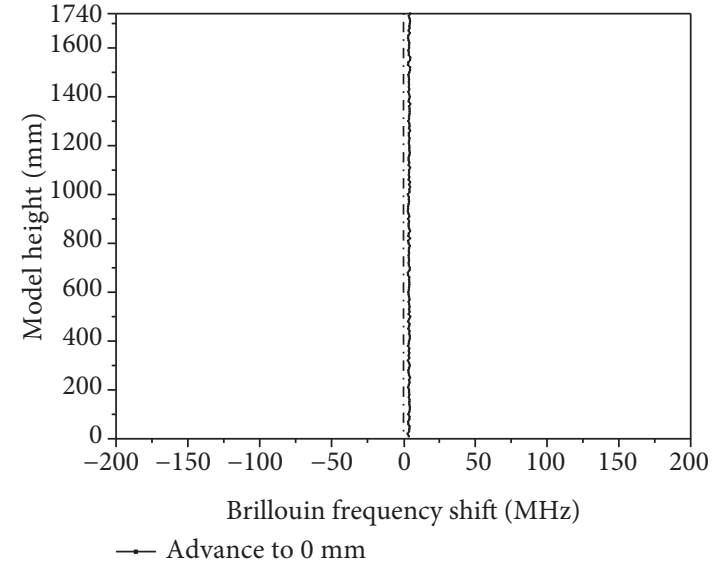

(a) Face 2 advance to $0 \mathrm{~mm}$

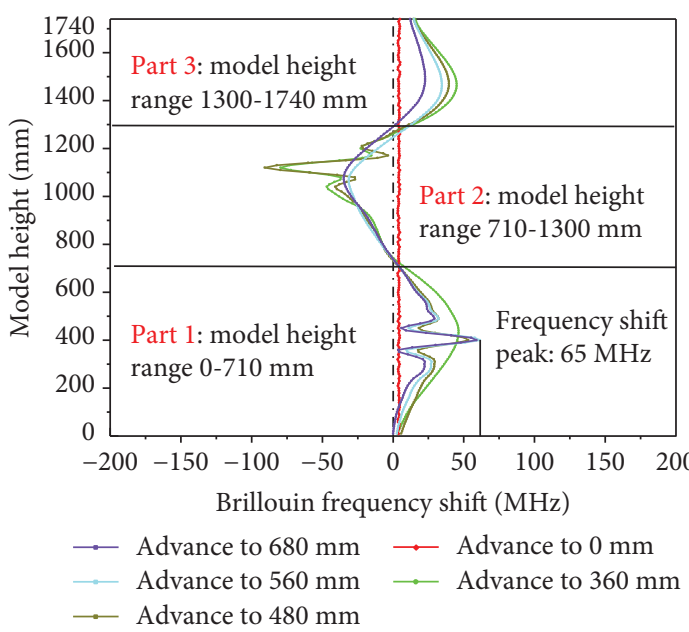

(c) Face 2 advance to $680 \mathrm{~mm}$

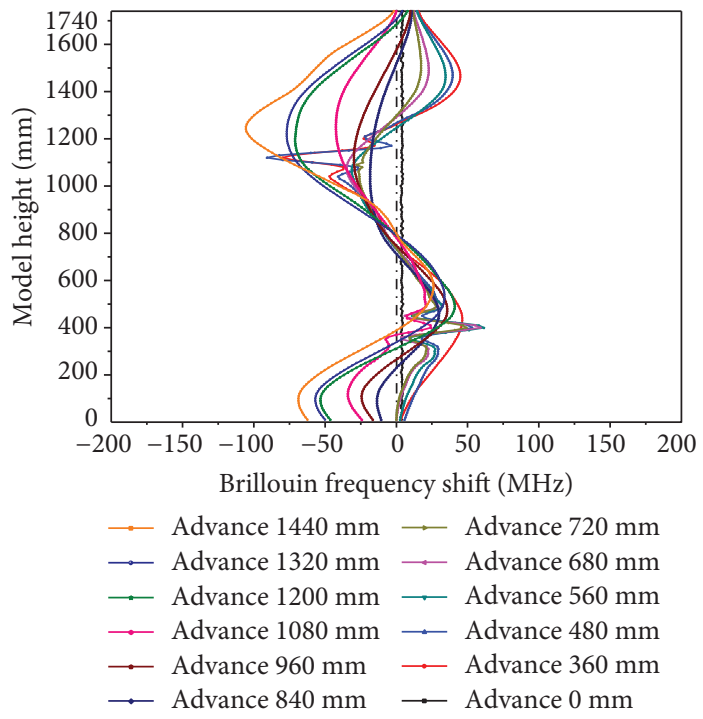

(e) Face 2 advance to $1440 \mathrm{~mm}$

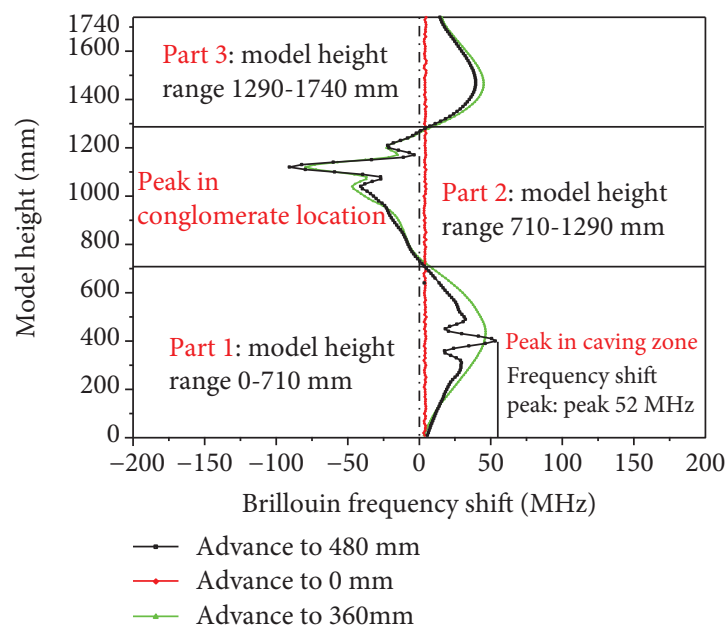

(b) Face 2 advance to $480 \mathrm{~mm}$

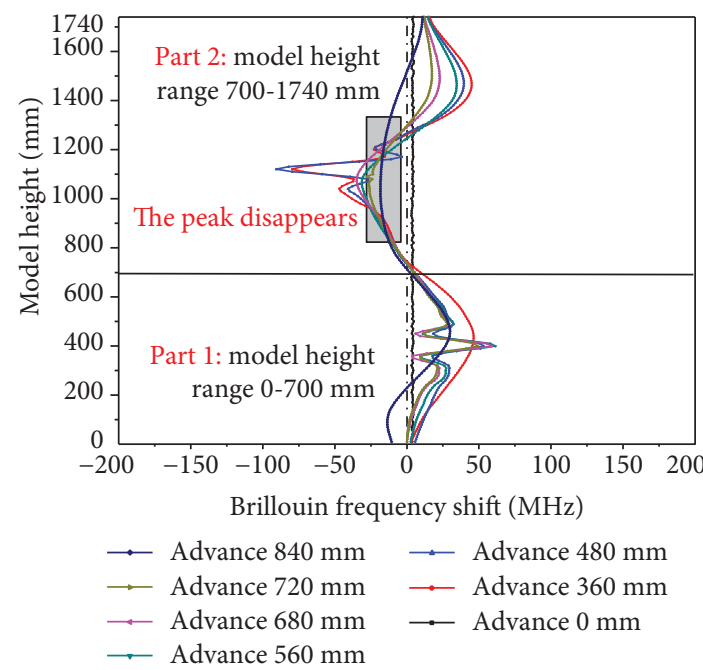

(d) Face 2 advance to $840 \mathrm{~mm}$

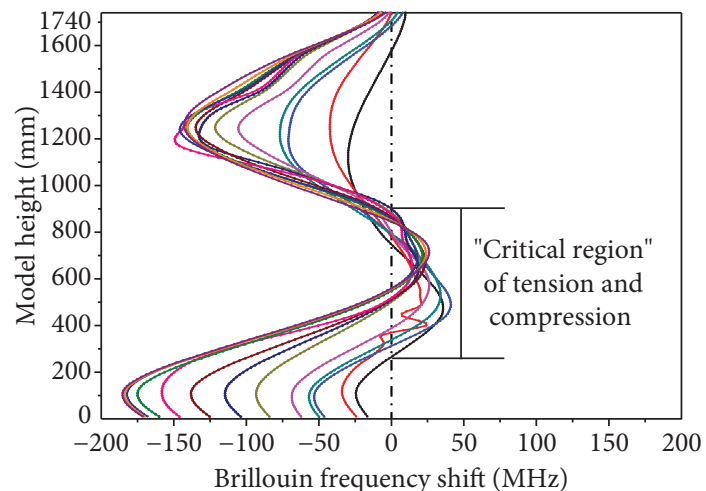

$\rightarrow$ Adcance to $2400 \mathrm{~mm} \rightarrow$ Adcance to $1560 \mathrm{~mm}$

$\longrightarrow$ Adcance to $2280 \mathrm{~mm} \longrightarrow$ Adcance to $1440 \mathrm{~mm}$

$\longrightarrow$ adcance to $2200 \mathrm{~mm} \longrightarrow$ Adcance to $1320 \mathrm{~mm}$

- Adcance to $2080 \mathrm{~mm} \mathrm{\longrightarrow}$ Adcance to $1200 \mathrm{~mm}$

- Adcance to $1960 \mathrm{~mm} \mathrm{\rightarrow} \mathrm{Adcance} \mathrm{to} 1080 \mathrm{~mm}$

- Adcance to $1840 \mathrm{~mm} \rightarrow$ Adcance to $960 \mathrm{~mm}$

$\rightarrow$ Adcance to $1680 \mathrm{~mm}$

(f) Face 2 advance to $2400 \mathrm{~mm}$

FIgURE 5: The optic fiber frequency shift of face 2 mining. 


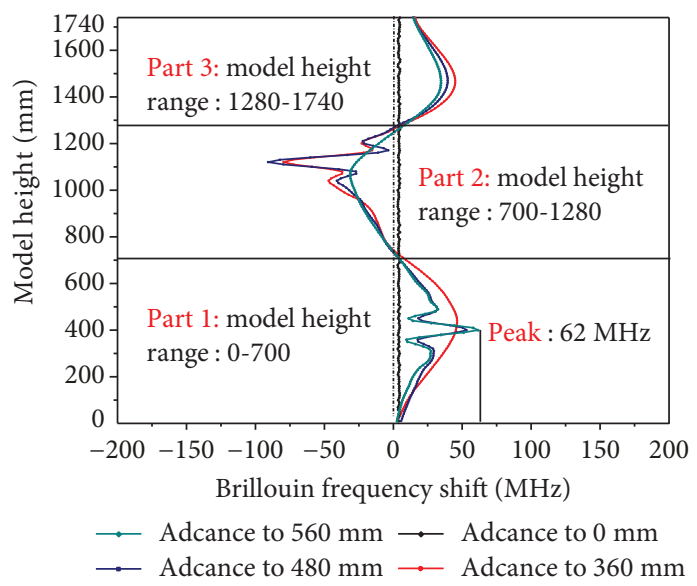

(a) Face 2 near $V_{11}$

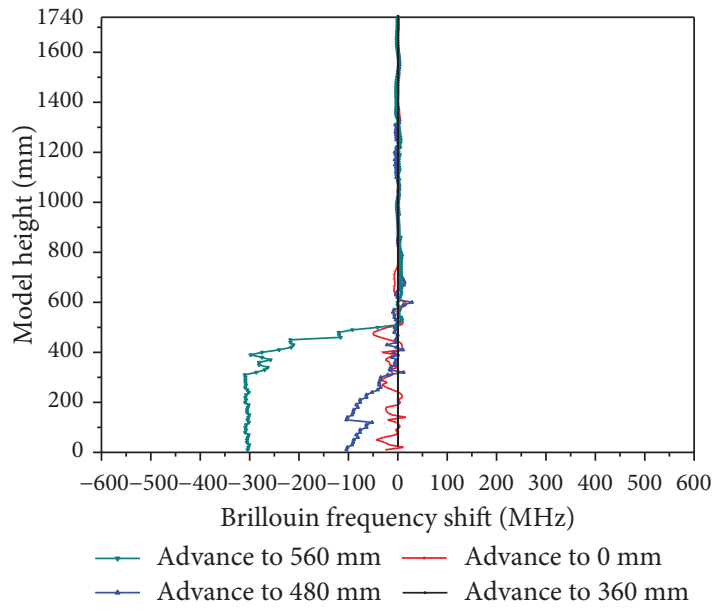

(b) Face 1 near $V_{11}$

Figure 6: Optic fiber $V_{11}$ 's frequency shift of face 2 and face 1 when near the fiber.

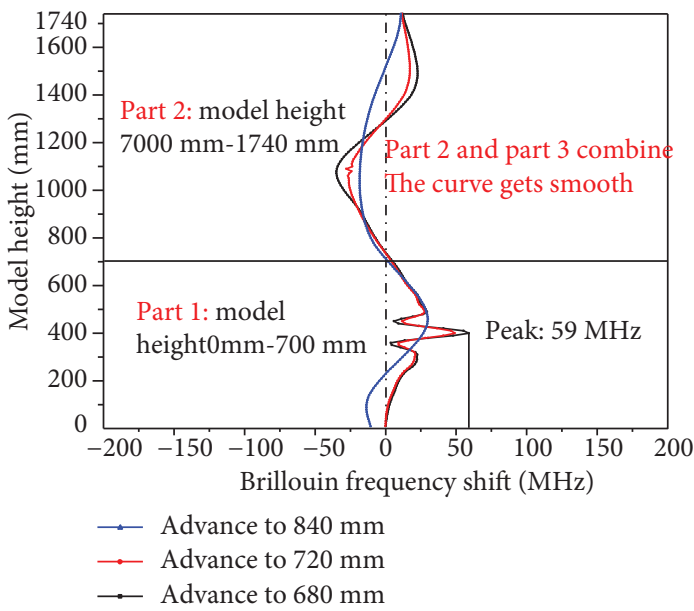

(a) Face 2 through $V_{11}$

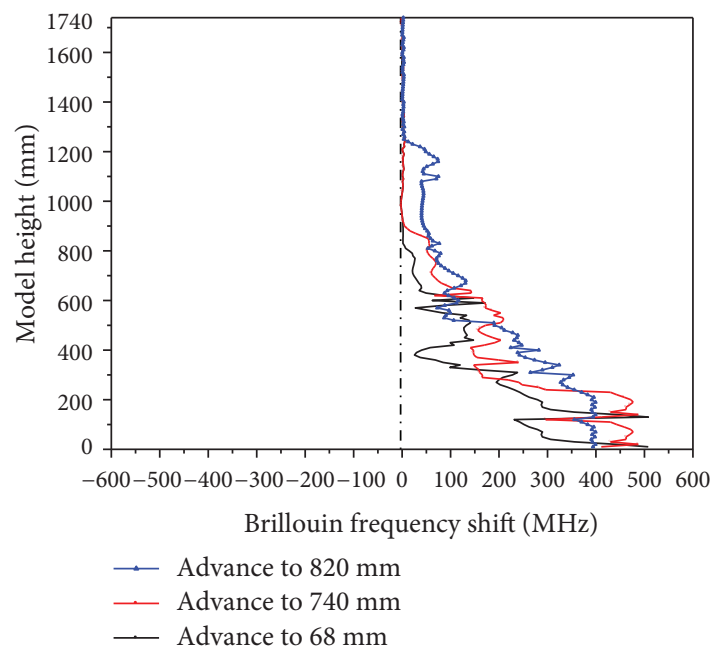

(b) Face 1 through $V_{11}$

Figure 7: Optic fiber $V_{11}$ 's frequency shift of face 2 and face 1 when through the fiber.

When working face 2 passed through the fiber, the accumulation elasticity energy of the key layer in the conglomerate layer had released, and the key stratum loses its support function due to the secondary disturbance, while the overburden on it is in the pressure state together. As shown in Figure $7(\mathrm{~b})$, when working face 1 passed through the optical fiber $V_{11}$, the fiber is in tension state in the range of $0 \sim 1200 \mathrm{~mm}$, and there is no obvious frequency shift change in the range of $1200 \sim 1740 \mathrm{~mm}$. The frequency shift peak is $+500 \mathrm{MHz}$, the frequency shift decreases as the model height increases gradually, and the range of surrounding rock deformation reached a height to $1200 \mathrm{~mm}$ position. The working face is advanced to the position of the fiber, and the rock formation in the fiber position is broken, but the deformation of the strata is different, which leads to the difference change of the frequency shift. Because the optical fiber and the surrounding rock are in close contact, when the strata is moving downwards, the optical fiber is in tension state by the friction of the surrounding rock, and the tensile stress decreases gradually with the increase in the model height. At this time, the fiber is located in the collapse area.

4.2.3. Working Face Away from the Fiber. Figure 8 shows the frequency shift curve of the two working faces in the process away from the fiber. Figure 8 (a) is face 2 away from the optical fiber; the measured data is the frequency shift value for the working face advanced from the 960 to $2400 \mathrm{~mm}$ region. As shown in the figure, most of the optical fiber is in the compression state, with the middle of the fiber in a state of tension.

According to the characteristic of the curve, the frequency shift is maximum in the height of the coal seam position, which is the core position of the caving zone, and the compressive stress is the largest. With the increase in the height, the absolute value of the frequency shift is gradually reduced, and most of the frequency shift is $0 \mathrm{MHz}$ in the 


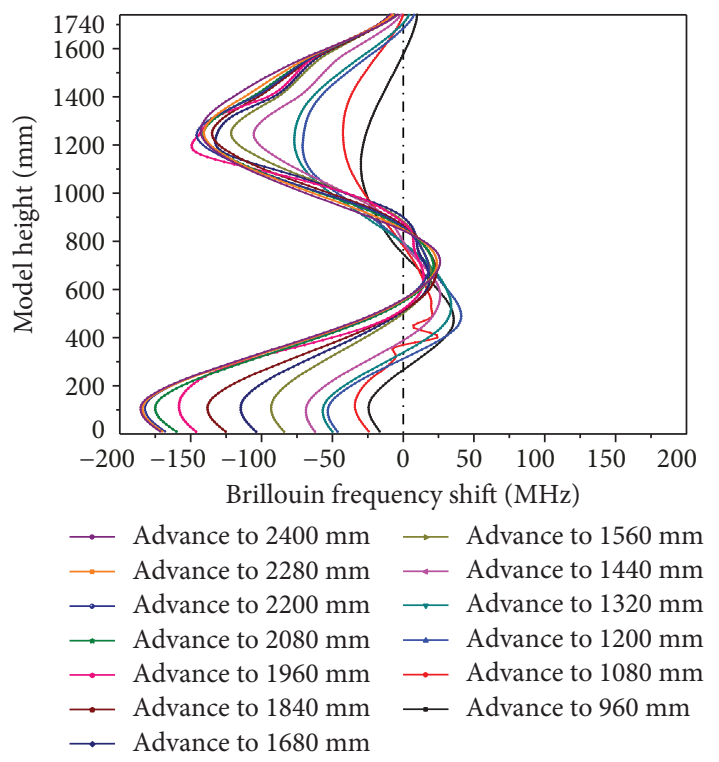

(a) Face 2 away from $V_{11}$

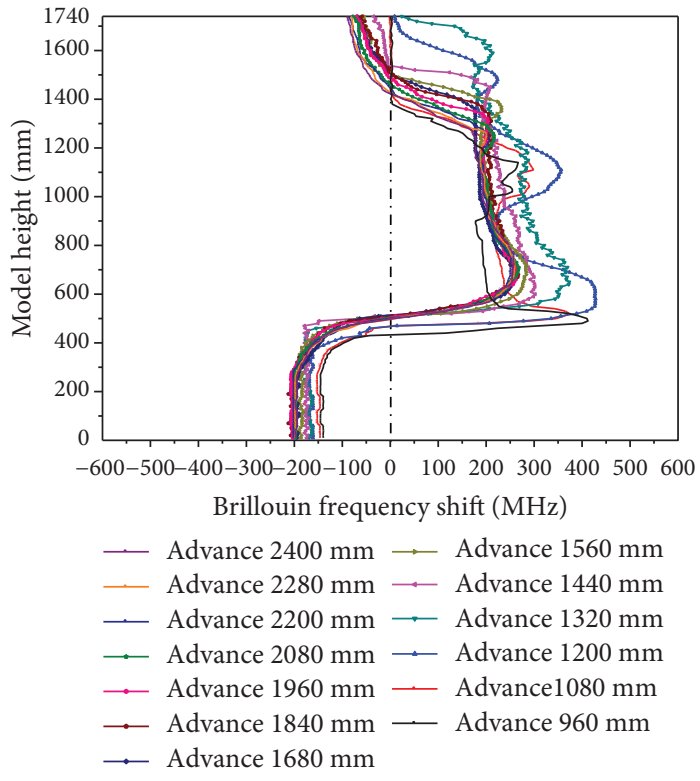

(b) Face 1 away from $V_{11}$

FIGURE 8: Optic fiber $V_{11}$ 's frequency shift of face 2 and face 1 when away the fiber.

height of $500 \mathrm{~mm}$, where the optical fiber is in the external stress balance. The 500 $850 \mathrm{~mm}$ range of the fiber is in the state of tension; the frequency shift monotonically decreases in the height range of 1200 1740 $\mathrm{mm}$ and finally returns to zero at the top of the model. The frequency shift curve shows a "hump" shape. Compared with the working face 1 mining process, as shown in Figure 8(b), working face 1 mining has obvious "step shape" changes, which can distinguish the different deformation degree of the surrounding rock.

4.3. Analysis of the Overlying Stratum Structure. Figure 9 shows the structure of the overburden based on optic fiber monitoring. There is no isolated coal pillar in the middle of the two working faces, and the key stratum is in the same group. The overburden moving range is small when face 1 mining, and the longitudinal fissure perforation forms the masonry structures. According to the real model photos and the monitoring data of the optical fiber, the range of the caving zone is about $0 \sim 500 \mathrm{~mm}$, and it is not extended to the key stratum of the conglomerate layer. The key stratum is in the fissure zone. The working face 2 is located inside the model and cannot directly observe the deformation condition. Therefore, it can only deduce the law of overlying rock movement through the distributed fiber monitoring results. From the analysis of results in "Optical Fiber Test Data", the key stratum structural damage occurred when working face 2 advanced to $840 \mathrm{~mm}$. Fractured rock blocks produced a rotation in a positive direction due to the support of the cantilever beam in the coal wall side, and the rock blocks of the key stratum above the face 1 caving zone produced a reverse rotation; both the rock blocks tilted toward the middle of the caving zone and produced an articulation. After the loss of the key layer support, the overlying strata above the working face further compacted in the mined-out area, leading to the compressive stress increasing the lower part of the fiber. Working face 2 mining results in a significant increase in ground surface subsidence on top of the model; according to the measured data, the amount of subsidence increased from 4.8 to $6.5 \mathrm{~cm}$.

\section{Experimental Discussions}

5.1. The Reliability of the Test. The distributed sensing fiber can be used to test the deformation of the surrounding rock in the physical model test and judge the working face pressure. But the coupling between the model material and the sensing fiber is worth exploring.

BOTDA optic fiber sensing technology to detect the deformation of the material or structure is to paste the sensor fiber or embed it in the structure by detecting the axial strain of the fiber itself to achieve structural deformation distributed monitoring. The contact relationship between the optical fiber and the material is a major factor affecting the monitoring results.

According to the results of analyses in Optical Fiber Test Data, compared with the previous monitoring data, the fiber response information gets single after face 2 advanced to $840 \mathrm{~mm}$, and the frequency shift curves do not have peak characteristics, and the curve is gradually gentle. The deformation of overburden increased dramatically after the instability of the key stratum, the surrounding rock and fiber will detach when the stratum produces an abscission layer and collapse, and the strain monitored by the optic fiber cannot characterize the stratum's deformation. Increasing the coupling between the model material and the sensing fiber is an effective way to solve the above problem. 


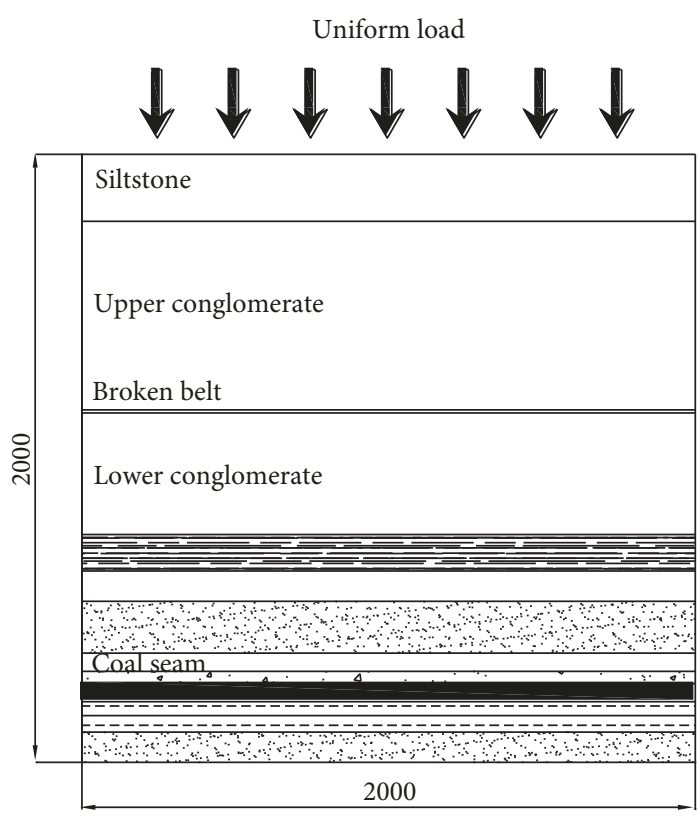

(a) The initial overburden structure

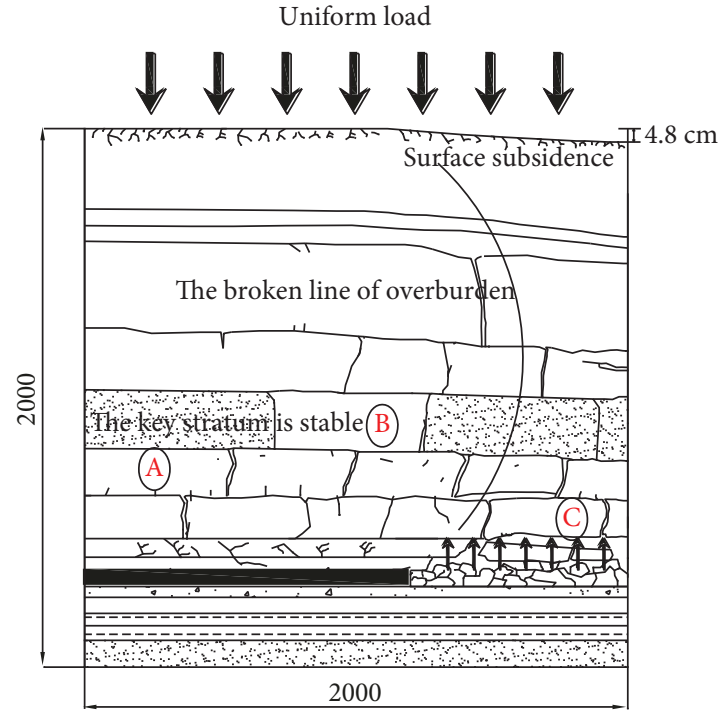

(b) The structure after face 1 mining

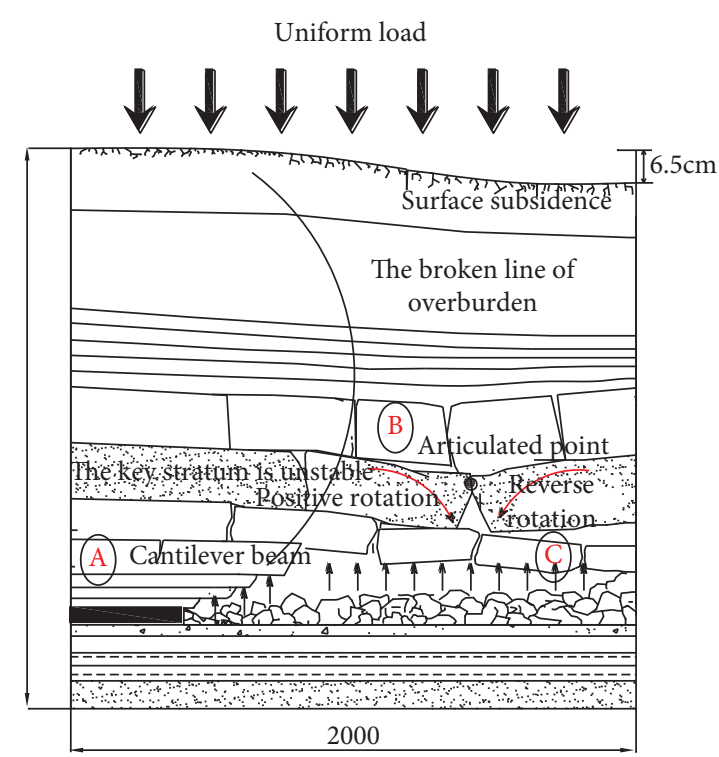

(c) The structure after face 2 mining

FIgURE 9: The picture of the model's overlying strata structure.

5.2. Ways to Improve. The test fiber is a $2 \mathrm{~mm}$ single-mode optical fiber. The optical fiber is prefixed to the specific position of the model frame and prepulled, and then laying similar materials on a layer-by-layer basis; no binder is used between the material and the optical fiber. Therefore, it is unavoidable that the rock is separated from the sensor fiber after a large deformation occurs.

It is now considered to solve the coupling problem from the performance, structure, and external binder of the fiber matrix material. The following is an example: choose the materials where the elastic modulus is similar to the model material to improve the optical fiber and the measured material strain transfer relationship; change the cylindrical packaging for the belt packaging or spiral packaging, or paste the small disc at a certain distance on the fiber; and choose adhesive materials with good compatibility with model materials and coating on the surface of the fiber. Such methods require further experiments to verify their effectiveness.

\section{Conclusions}

In this paper, by analyzing the distributed optical fiber arranged in the three-dimensional physical model, the overburden deformation of adjacent coal face mining is studied, and the following conclusions are drawn: 
(1) After the adjacent working face was mined, the secondary disturbance broke the stress balance of the surrounding rock and the stress distribution of the surrounding rock redistributed. Before the working face advanced to $840 \mathrm{~mm}$ (near the fiber), the stress law of overburden was as follows: the middle of the model is under pressure and the remaining is under tension, with the secondary mining causing the key stratum stress concentration

(2) When the face advanced to $840 \mathrm{~mm}$ (through the fiber), the frequency shift curves of the key stratum and the strata on it combined, the frequency shift curves do not have peak characteristics, and the stress concentration in the stratum disappeared, indicating that the bearing structure of the key stratum gets unstable

(3) Compared with the previous monitoring data, when the working face is far away from the fiber, the information reacted by the frequency shift gets single, the overburden's deformation increased after the key stratum gets instable, and the surrounding rock and fiber will detach when the stratum produces an abscission layer and collapses, yet the strain monitored by the optic fiber cannot characterize the strata's deformation

\section{Data Availability}

The data used to support the findings of this study are available from the corresponding author upon request.

\section{Conflicts of Interest}

The authors declare that they have no conflicts of interest.

\section{Acknowledgments}

The authors thank funds supported by the Key Program of the National Natural Science Foundation of China (No. 51174280).

\section{References}

[1] G. Lu, Research on Residual Coal Workability Evaluation and Remaining Technology of Aged Coal Mine [Ph. D. Thesis], China University of Mining and Technology, Beijing, 2010.

[2] G. R. Feng, J. Zheng, Y. F. Ren, X. X. Wang, L. X. Kang, and H. F. Liu, "Decision theory and method on feasibility on the upward fully mechanized mining of the left-over coal above gob area mined with caving method," Journal of China Coal Society, vol. 35, no. 11, pp. 1863-1867, 2010.

[3] M. He, G. Li, J. Wang, and J. Cai, "Study on supporting design for large area serious roof caving of deep soft rock roadway in Xing An coal mine," Chinese Journal of Rock Mechanics and Engineering, vol. 26, no. 5, pp. 959-964, 2007.

[4] X. Fang, M. Guo, and Z. Lu, "Instability mechanism and prevention of roadway under close-distance seam group mining," Chinese Journal of Rock Mechanics and Engineering, vol. 28, no. 10, pp. 2059-2067, 2009.
[5] M. Qian and P. Shi, Ground Pressure and Stratum Control, China University of Mining and Technology Press, Xuzhou, 2003.

[6] B. Shi, X. J. Xu, D. Wang et al., "Study on BOTDR-based distributed optical fiber strain measurement for tunnel health diagnosis," Chinese Journal of Rock Mechanics and Engineering, vol. 24, no. 15, pp. 2622-2628, 2005.

[7] T. Horiguchi and M. Tateda, "Optical-fiber-attenuation investigation using stimulated Brillouin scattering between a pulse and a continuous wave," Optics Letters, vol. 14, no. 8, pp. 408-410, 1989.

[8] H. Ohno, H. Naruse, M. Kihara, and A. Shimada, "Industrial applications of the BOTDR optical fiber strain sensor," Optical Fiber Technology, vol. 7, no. 1, pp. 45-64, 2001.

[9] K. de Souza and T. P. Newson, "Signal to noise and range enhancement of the Brillouin intensity based temperature sensor," Optics Express, vol. 12, no. 12, pp. 2656-2661, 2004.

[10] A. Mendez, T. F. Morse, and F. Mendez, "Applications of embedded optical fiber sensors in reinforced concrete buildings and structures," Fiber Optic Smart Structures and Skins II, vol. 60, no. 2, pp. 60-69, 1990.

[11] M. A. Soto, G. Bolognini, F. di Pasquale, and L. Thévenaz, "Simplex-coded BOTDA fiber sensor with $1 \mathrm{~m}$ spatial resolution over a $50 \mathrm{~km}$ range," Optics Letters, vol. 35, no. 2, pp. 259-261, 2010.

[12] S. Martin-Lopez, M. Alcon-Camas, F. Rodriguez et al., "Brillouin optical time-domain analysis assisted by second-order Raman amplification," Optics Express, vol. 18, no. 18, pp. 18769-18778, 2010.

[13] X. Liu, "On the application of fiber optical sensor to geomechanics and geo-technical engineering," Chinese Journal of Rock Mechanics and Engineering, vol. 18, no. 5, pp. 588-591, 1999.

[14] J. Chai, L. Zhu, S. Wei et al., "Settlement deformation detecting in deep unconsolidated soil layer by fiber Bragg grating sensing technology," Journal of China Coal Society, vol. 34, no. 6, pp. 741-746, 2009.

[15] J. Chai, Q. Liu, J. Liu, and D. Zhang, "Optical fiber sensors based on novel polyimide for humidity monitoring of building materials," Optical Fiber Technology, vol. 41, pp. 40-47, 2018.

[16] T. Kurashima, T. Horiguchi, H. Ohno, and H. Izumita, "Strain and temperature characteristics of Brillouin spectra in optical fiber for distributed sensing techniques," in 24th European Conference on Optical Communication. ECOC '98 (IEEE Cat. No.98TH8398), pp. 2-24, Madrid, Spain, September 1998.

[17] J. Chai, W. Du, Q. Yuan, and D. Zhang, "Analysis of test method for physical model test of mining based on optical fiber sensing technology detection," Optical Fiber Technology, vol. 48, pp. 84-94, 2019.

[18] T. Horiguchi and M. Tateda, "BOTDA-nondestructive measurement of single mode optical fiber attenuation characteristics using Brillouin interaction: theory," Journal of Light wave Technology, vol. 7, no. 8, pp. 1170-1176, 1989. 


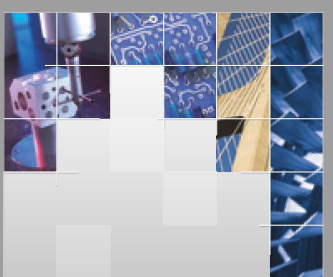

\section{Enfincering}
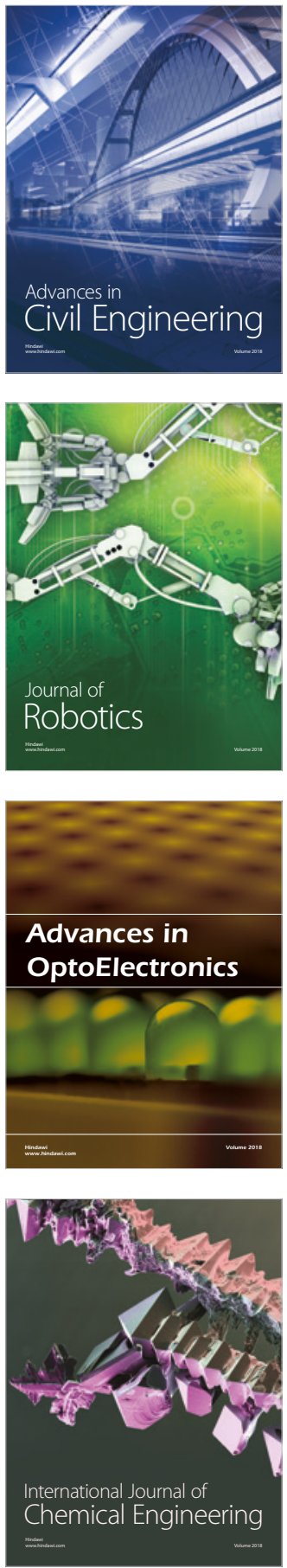

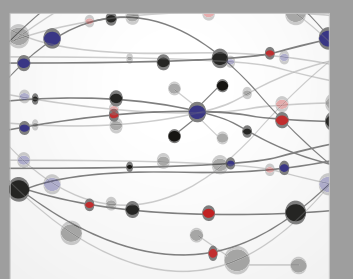

\section{Rotating \\ Machinery}

The Scientific World Journal

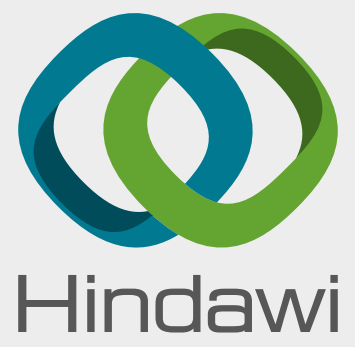

Submit your manuscripts at

www.hindawi.com
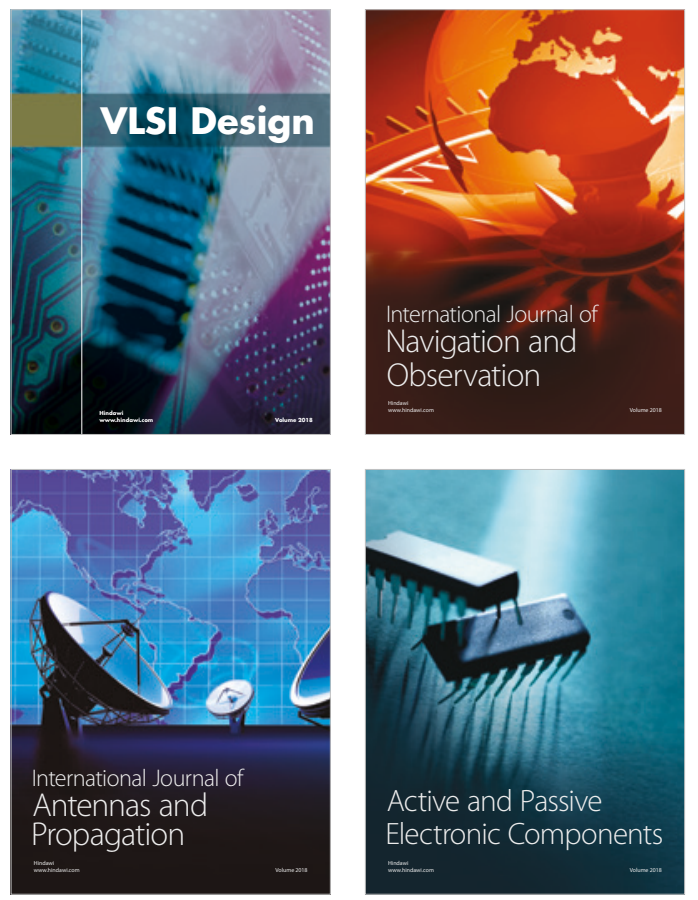
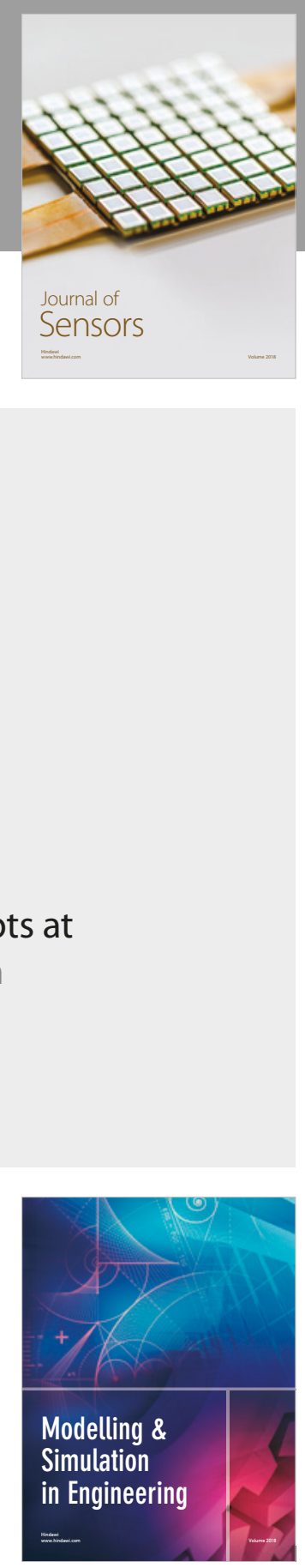

\section{Advances \\ Multimedia}
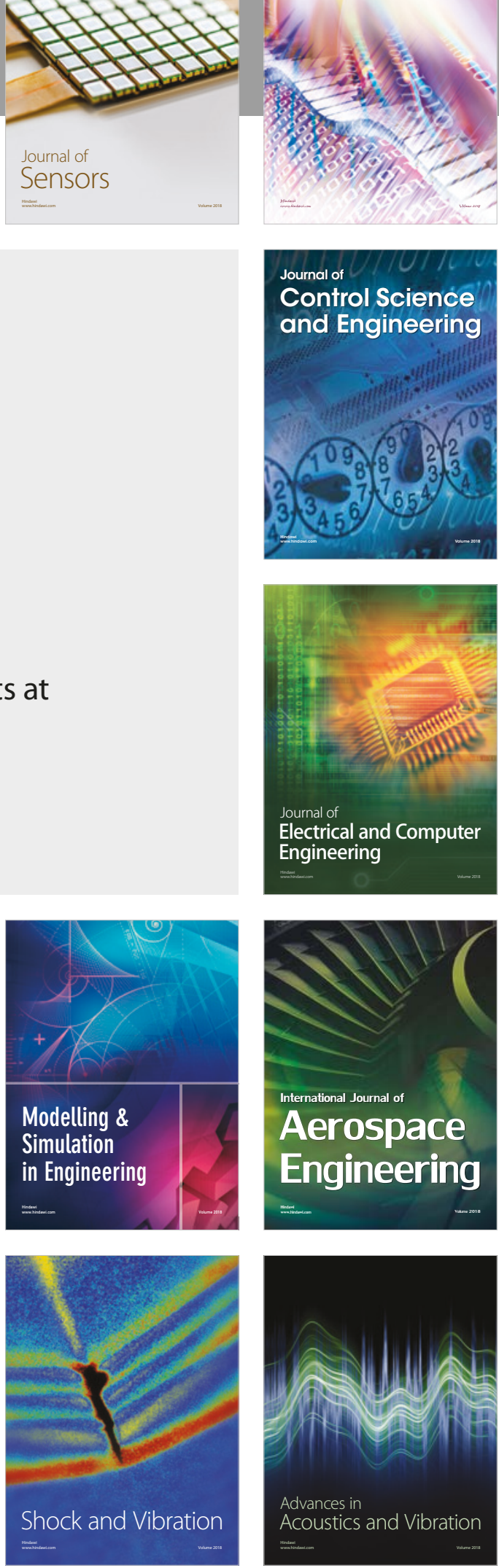